\title{
TOO BIG TO IGNORE: LATO SENSU BUSINESS STUDENTS' PERCEPTIONS ON AN ACCOUNTING BIG DATA CASE
}

\author{
Vitor Hideo Nasu ${ }^{1}$ \\ Daniel Ramos Nogueira ${ }^{2}$ \\ Elvis Araujo Albertin ${ }^{3}$ \\ Claudio Marques ${ }^{4}$
}

\begin{abstract}
The objective of this study was to analyze the perceptions of lato sensu business students on an accounting big data case. The case was developed by Hoelscher and Mortimer (2018) and was designed to be used with the Tableau software. It was implemented in two distinct accounting courses from two higher education institutions located in the South region of Brazil. Right after the end of the case's development, surveys were administered to collect data from the 41 participants. Survey questions were divided into three sections: (i) student's demographic information; (ii) student's proficiency level in Excel, Tableau, and Statistical software packages; and (iii) ten case-related and Tableau-related questions that were extracted from prior literature. According to the descriptive statistics, most of the students had low proficiency levels in Tableau before the case's implementation. After the case, students' perceptions changed from "none" to "basic" regarding their proficiency level. Also, students found the case interesting, engaging, and useful. It helped them to gain an understanding of how data analytics can be used to answer crucial business questions. Results from the association tests indicated that the students' demographic and academic information is not significantly associated with the case-related and Tableau-related questions. It means that students who majored in accounting and non-accounting areas had similar perceptions. Then, the case has shown to be a productive activity even for those whose academic background is not directly related to the accounting field. Finally, students' comments reinforced the positive experience with the case.
\end{abstract}

Keywords: Big data. Educational case. Business students. Accounting education. Survey.

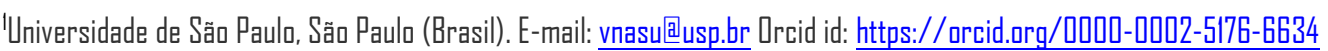

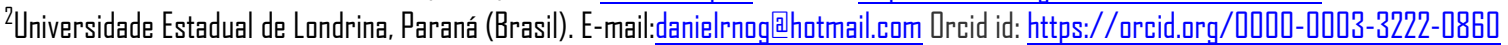

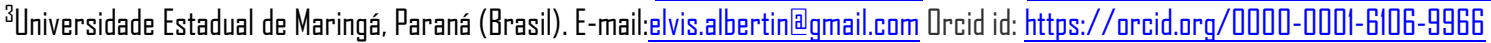

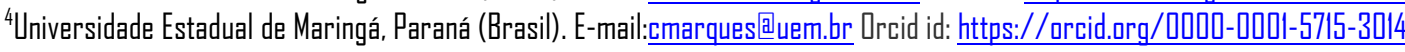




\section{INTRODUCTION}

University of Sao Paulo Accounting Professor Eliseu Martins indicates in the syllabus of the EAC5860 Teorias do lucro e da avaliação patrimonial course that today's most modern vision makes accounting a big database that can and must be aggregated according to the needs of each user, at each moment, for each distinct purpose. On a daily basis, accounting professionals face huge amounts of financial data generated by the company's economic transactions.

From an intuitive perspective, to this great heap of data is given the name of big data. However, the concept of big data goes beyond the quantity of information, comprising its variety and high-speed processing aspects as well (Günther, Rezazade Mehrizi, Huysman, \& Feldberg, 2017; Laney, 2001; Lindell, 2018). Vasarhelyi, Kogan, and Tuttle (2015) also point out that the term big data has been utilized by many areas and therefore its meaning can differ across disciplines and even within a field. In accounting, for instance, Vasarhelyi et al. (2015) indicate that what can be considered big data for small accounting business is not the same for big accounting corporate companies. Despite that, high volume, variety, and velocity seem to be the common ground when it comes to the concepts that big data can assume.

Big data analytics was only possible because of the advancements in technology, which allowed more effective and automated processes. It made Richins, Stapleton, Stratopoulos, and Wong (2017) reflect upon the extinction of the accounting profession, mainly because "data analytic techniques applied to Big Data [...] have the potential to replace many of the tasks traditionally performed by accountants and auditors" (p. 63).

Likewise, Pincus, Stout, Sorensen, Stocks, and Lawson (2017) consider automation a force for change accounting higher education as it is increasing the skill gap for finance and accounting jobs. Accountants are lagging behind in the run of obtaining technology competency to manage big data. In contrast, information technology (IT) professionals may already have these skills once they are constantly working with data processing through IT resources. It might be due to this that non-accounting professionals with data analytics skills will gather audit evidence easier than ever before because data analytic and visualization methods 
are advancing, making space for them to entry the audit business (Brown-Liburd \& Vasarhelyi, 2015; Earley, 2015).

In reaction to this change, the Journal of Accounting Education (JAEd) published in 2017 a special issue on big data in accounting, including educational cases. This initiative helps to bring big data and accounting education together to reduce the skill gap in terms of data analytic. However, the teaching of big data in accounting courses in Brazil is incipient - it may also be the case of some other countries - and thus this is opportune to use an accounting big data case to encourage business students to work their data analysis and visualization skills. Since it is one of the first experiences of teaching big data using an accounting case in Brazil, the aim of this study is to verify the students' perceptions on an accounting big data educational case regarding its potential to increase learning while using Tableau, a specific software package for data visualization.

This study contributes to the prior national literature by bringing preliminary evidence on a big data case applied to classes from two lato sensu accounting programs in Brazil. Arguably, students' perception is relevant to improve both the quality of teaching and the assessment of the suitability of the case for their professional lives. By analyzing the association of students' characteristics and their responses to the cases, this study also contributes to providing evidence on which student profile benefited more from the case, especially when considered their academic background.

The remainder of the paper is organized as follows. Section 2 presents the literature review. Section 3 reports the methodological procedures. Section 4 brings and discusses the results and section 5 concludes.

\section{LITERATURE REVIEW}

\subsection{BIG DATA AND THE ACCOUNTING PROFESSION}

Volume, velocity, and variety are the three Vs of the big data's concept proposed by the Laney's (2001) 3D data management model. Other two Vs, veracity and value, were also added to the model by prior literature (Bello-Orgaz, Jung, \& Camacho, 2016; Blazquez \& Domenech, 2018; Gandomi \& Haider, 2015; Wamba et al., 2017; Zhang, Yang, \& Appelbaum, 2015), making a 5V model. 
Volume is what makes big data to be called big data and refers to the size of data (Coyne, Coyne, \& Walker, 2018; Gandomi \& Haider, 2015). Businesses receive large amounts of data from multiple types of sources, including their own data management systems and social network webpages. Data are usually reported in terabytes or petabytes (=1024 terabytes) due to their big size. According to Gandomi and Haider (2015), the definition of volume is relative and can vary across time and type of data. Because technology is always in evolution, what we called a huge amount of data today may not be the same in the future as the data storage capacity increases.

One could think that velocity would refer only to the speed at which data are generated, but it embraces other aspects. Velocity has to do with "the rate at which data are generated and the speed at which it should be analyzed and acted upon" (Gandomi \& Haider, 2015, p. 138). Beaver, Kumar, Li, Sobel, and Vajgel (2010) indicate that one million pictures per second are processed by Facebook, but as important as capturing these data is how and when to analyze them to create competitive edge (Wamba et al., 2017). Internet and mobile devices have been playing essential roles since individuals can take, share, send, and buy pictures, messages, posts, and products in real-time and wherever they are.

Variety represents the nature of the data. It refers to their "structural heterogeneity in a dataset" (Gandomi \& Haider, 2015, p. 138). Advancements in technology allowed companies to collect data from multiple sources. Some authors discuss data in the light of two or three structural categories: (i) structured, (ii) semi-structured, and (iii) unstructured (Bello-Orgaz et al., 2016; Coyne et al., 2018; Gandomi \& Haider, 2015; Warren, Moffitt, \& Byrnes, 2015; Zhang et al., 2015). Structured data are just a small part (5-10\%) of all of the possible collectable data (Gandomi \& Haider, 2015; Warren et al., 2015), and they present high levels of homogeneity (e.g., responses from a multiple choice question). On the other hand, unstructured data are disorganized, and they are barely comparable without previous treatment. Images and comments from social media platforms often are unstructured. Semi-structured data presents both characteristics from the two prior categories but at more reasonable levels. They are not totally structured nor are they totally unstructured but can present some parts that are more equal and comparable while others are not. 
The business world has always been competitive and then some of its professionals have behaved immorally. Moreover, digital frauds and fake news are more frequent as the Internet attracts more users, making much data and sources questionable. In this context, veracity is crucial to guarantee that decisions are being taken based on reliable data. Also, people are subject to errors and emotions when providing data (e.g., through online surveys), influencing their level of reliability. Companies should consider these aspects and desirably develop mechanisms to mitigate the lack of precision and uncertainty on the data (Gandomi \& Haider, 2015). Veracity then refers to the correctness and accuracy of the data (Bello-Orgaz et al., 2016), regardless their motives to not present these characteristics.

The final V - value - represents the extent to which the data can provide competitive advantage for the companies. It is connected with other big data's dimensions (e.g., volume and veracity) and at the same time is fundamental for them. According to Gandomi and Haider (2015), "big data are worthless in a vacuum. Its potential value is only unlocked when leveraged to drive decision making" (p. 140). Value also depends on the companies' strategic goals and the purpose of using big data (Günther et al., 2017). "For each company, the usefulness of the data is limited by quantity, quality, and accessibility" (Warren et al., 2015, p. 404). It means that some companies do not collect enough data to extract useful analyses, or the data are unreliable or irrelevant, or still entities do not have the expertise and tools to deal with huge amounts of data. The value dimension is crucial because it makes the management reflects on whether the adoption of big data's tools is worthy for the company.

All five Vs are related to accounting information and, for this reason, big data may even influence accounting standards in the near future (Warren et al., 2015). More shortly, it can happen with accounting practices. For instance, FIFO, LIFO, and average costing make assumptions about the cost of goods because tracking inventory items involve high costs. However, radio frequency identification (RFID) technology is changing this scenario. Its tags are cheap, small, fully machine-readable, and detectable over short spans of space (Krahel \& Titera, 2015). RFID tags could be used to track each item of an inventory, precising the cost of good and providing users more accurate accounting information. Its use has already been beneficial to a range of industries (Krahel \& Titera, 2015). 
Auditing is also feeling the impact of big data (Alles \& Gray, 2016; BrownLiburd \& Vasarhelyi, 2015; Cao, Chychyla, \& Stewart, 2015; Earley, 2015; Krahel \& Titera, 2015; Yoon, Hoogduin, \& Zhang, 2015; Zhang et al., 2015). Big data has been under analysis by auditing researchers because the power of technology to monitor management practices have increased, making audit evidence faster, useful, and more reliable to be obtained. Brown-Liburd and Vasarhelyi (2015), for example, put that "organizations will eventually embed chips into their inventory and fixed assets, use mobile trackers on equipment and employees, and have smart devices in most of their facilities, managing access, location, environmental parameters, and dynamic behavior" (p. 3). It all contributes to gather audit evidence from accounting and management practices.

In financial accounting, Warren et al. (2015) discuss how off-balance sheet assets and fair value will be affected by big data. There is information that is not disclose through the use of financial statements, such as product quality, human resources, company's reputation and so forth. Big data's algorithms and data mining could assist in providing some evidence or additional information about an asset. For instance, analyses from the comments on Facebook and/or Twitter about a company's product or service would be valuable subsidies for analysists and other stakeholders to start pricing off-balance items that are hard to measure financially. These analyses could be reported with the financial statements as explanatory notes.

The accounting profession has always been familiar with data management systems, from the very rudimentary to the most innovative one. But due to the high volume, speed, and variety of the data, effective accounting technologybased systems are needed more than ever to provide managers and accountants with timely feedback. "Big data has become increasingly important to multiple facets of the accounting profession, but accountants have little understanding of the steps necessary to convert big data into useful information" (Coyne et al., 2018, abstract). It represents a threat to the profession because other practitioners can also provide the services that are currently being provided by accountants (Brown-Liburd \& Vasarhelyi, 2015; Earley, 2015; Richins et al., 2017).

If accounting does not start educating its future professionals for a changing environment embedded with technology, big data will make accountants obsolete as it creates new forms of providing financial services. Changes in 
technology are reshaping how accountants deal with data, as well as the policies and processes of the profession (Pathways Commission, 2012). Therefore, accounting education needs to keep pace with the changes brought by big data through the incorporation of it into the accounting curriculum, including data visualization, integrated audit modules, database dashboard metrics, and so on (Pathways Commission, 2012).

Future accountants should learn to deal with big data not only from a threat perspective, but also to find opportunities to improve the profession. At the same time big data brings challenges, it opens doors for accountants to explore it. Richins et al. (2017) debate some opportunities accounting can take advantage of big data. For example, data scientists may be good at identifying patterns in financial data, but accountants are more trained to extract interpretations that can be turned into strategies (Richins et al., 2017). Either way, accounting education needs to implement big data contents to stay up to date with the changings in the profession.

\subsection{RELATED WORK}

There are some efforts to implement big data into the accounting curriculum. Despite that, the authors of this study were not able to find any published paper on an accounting course that has incorporated big data content in Brazil and has been teaching it beyond the theoretical level (e.g., with specific data analysis software and practical cases). Thus, some studies found internationally are described, especially those published in the special issue of the JAEd.

Janvrin, Raschke, and Dilla (2014) developed and applied a case (The Flecther Company) where the students assume the position of a divisional controller who needs to make decisions about the pricing and product-line strategies. This case aims to increase students' technology and communication competencies, especially in conjunction with the use of interactive data visualization (IDV) tools. Janvrin et al. (2014) administered surveys in the beginning and at the end of the case to measure students' perception and to collect evidence about the case's efficacy. In general, it was a positive and efficient educational experience. From quantitative data, students reported a significant 
increasing in their ability to organize complex accounting data, generate graphs in Excel and IDV programs, and to use software to build models and simulations. From qualitative data, students commented that the case introduced them to new data visualization concepts and helped to understand why data visualization is important.

Igou and Coe (2016) describe the Vistabeans coffee shop case in which students take the place of Alma Nelson, the CFO of the company, and must develop a profitability report with the support of Tableau, a specialized data visualization software. The intention is to submit the students to visual analysis so that they find ways to maximize the company's profits. Igou and Coe (2016) also conducted pre- and post-case surveys. The results indicated significant changes in how students perceived their understanding of big data before and after the case. Students' responses were significantly higher in the post-case survey than in the pre-case one, supporting that students have learned about how data analytics can be used to answer important business questions, how to use computer software to explore large volumes of data and communicate insights, how to use data analytics software to visualize data, among other big data analytics skills.

Janvrin and Watson (2017) developed a commentary-paper type for the special issue of the Journal of Accounting Education. In their work, they argue that the primary goal of accounting is to create and provide relevant information to internal and external users for decision-making purposes, regardless the development of data analytic software and large datasets. In addition, they also provide resources - software, and datasets - for incorporating big data into accounting courses, including the Big Data University software (IBM) (http://bigdatauniversity.com/), Tableau (https://public.tableau.com/s/resources), and Teradata (http://www.teradatauniversitynetwork.com/). For more information, see tables 1 and 2 from Janvrin and Watson (2017).

Hoelscher and Mortimer (2018) developed and utilized the Ivana's ice cream case in which students must act as a business consultant for this company. The main task is to use the Tableau software to analyze data from the "first two quarters of operations and to provide a detailed breakdown of sales, product mix, and gross profit by product line and geographic region" (p. 49). In addition, because Ivana wants to expand the business in future years, students 
(consultants) were also asked to provide insights and suggestions. The case develops essential competencies that are consistent with AACSB Accounting Standard 7 and AICPA Accounting and Professional Competencies. Results indicate that most of the students (59.26\%) exceeded the expectations in terms of performance (correctly answered all questions), following by those who met the expectations (35.80\%; correctly answered all but one or two questions), and those who did not meet the expectations (5.94\%; incorrectly answered three or more questions). However, as a first experience in applying the case, Hoelscher and Mortimer (2018) considered the results very positive, especially because it showed the case's efficacy. Data from surveys showed that the case was engaging and a good learning experience.

\section{PROCEDURES}

\subsection{PARTICIPANTS}

The participants of the study were 52 students from two lato sensu accounting programs of two different higher education institutions located in the South region of Brazil. However, 11 students did not take part in this research because they did not show up on the day the surveys were administered. Therefore, responses were collected from a total of 41 students, of which twentyone students were female (51.22\%). Twenty-six students $(63.41 \%)$ majored in accounting, nine $(21.95 \%)$ in management, and six (14.63\%) in other fields, such as economics and human resource management. The average age of the students was 27.54 years, with a standard deviation of 4.11 years.

Although "this case is intended to be utilized in an undergraduate accounting information systems course; an introductory managerial course; or a course focusing on data analytics as a basic introduction to data visualization software" (Hoelscher \& Mortimer, 2018, abstract), the authors chose to use it in lato sensu graduate courses because these students may not have had the opportunity to attend big data classes during their undergraduate programs, since teaching big data in accounting programs in Brazil is incipient. Moreover, the authors presumed that students were not familiar with data visualization software (i.e., Tableau) and that it would be a productive experience for them. This 
assumption revealed to be right, as shown in Table 2 (students' low proficiency level in Tableau).

\subsection{CASE DEVELOPMENT}

The Ivana's ice cream case was developed by Hoelscher and Mortimer (2018) and is briefly described in the end of subsection 2.2. One of the authors of this study contacted (Hoelscher \& Mortimer, 2018) and asked for the case's data and permission to utilize them in accounting courses in Brazil. The author who asked for the data was also the one who was the professor of the two courses in which the big data case was implemented. One class worked with it in February 2019 and the other in March 2019. Because Ivana's ice cream case was designed to be used along with Tableau and this software is not free, the authors of this study used its trial version in one lato sensu program and the free university license in the other one. Both worked adequately for the learning goals of the courses. For confidentiality purposes, the names of the higher education institutions, programs, and students will not be disclosed.

Ivana's ice cream case was conducted in both classes identically. It was used in one class, which was divided into two parts. In the first one, the professor provided instructions about the case and the Tableau software. He also did some exercises along with the students. In the second part, the students received a list of questions to do without the support of the professor. These exercises mainly involved analyses through data visualization and were based on prior studies. Altogether, these two parts took about three hours.

According to Hoelscher and Mortimer (2018), the learning goals of the Ivana's ice cream case were aligned with AACSB Accounting Standard 7, including: "1. applying data analytics to understand company data, 2. utilizing data visualization software to present results needed to make key business decisions, 3. Applying data analytics to observe key data trends, 4. applying data analytics to enhance the business decision-making process, and 5. enhancing verbal and written communication skills to effectively disseminate data trends and business recommendations." (p. 54). Professional and accounting competencies were consistent with AICPA Accounting and Competencies as well (Hoelscher \& 
Mortimer, 2018). For more details of the Ivana's case, please see Hoelscher and Mortimer (2018).

\subsection{INSTRUMENT}

Data were collected through surveys right after the end of the application of the case. Besides students' demographic information, the survey comprised questions about students' proficiency level in (i) Excel, (ii) Tableau, and (iii) statistical software packages, such as Stata, SAS, R, and so on. Students had to respond based on four alternatives: None, Basic, Intermediate, and Advanced. Specifically for the proficiency level questions, the authors were able to gather data on the students' perception before and after the implementation of the case. All other questions were asked only after the case.

Case-related and Tableau-related questions were also asked, with which students needed to report their level of agreement. Table 1 shows the questions' description.

Table 1: Survey questions

\begin{tabular}{|c|c|c|}
\hline Item & Description & Literature \\
\hline Q1 & I found the case engaging and interesting & $\begin{array}{l}\text { Hoelscher and } \\
\text { Mortimer (2018); } \\
\text { Igou \& Coe (2016) }\end{array}$ \\
\hline Q2 & $\begin{array}{l}\text { I found the case to be an effective way to gain an } \\
\text { understanding of how data analytics can be used to } \\
\text { answer important business questions. }\end{array}$ & Igou \& Coe (2016) \\
\hline Q3 & $\begin{array}{c}\text { I found the case to be an effective way to gain an } \\
\text { understanding of data analytics software. }\end{array}$ & Igou \& Coe (2016) \\
\hline Q4 & $\begin{array}{l}\text { I found the case to be an effective way to develop skills } \\
\text { and knowledge related to data analytics. }\end{array}$ & Igou \& Coe (2016) \\
\hline Q5 & I think that this case should be used in future classes & Igou \& Coe (2016) \\
\hline Q6 & I used a variety of skills to solve this case & $\begin{array}{l}\text { Hoelscher and } \\
\text { Mortimer (2018) }\end{array}$ \\
\hline Q7 & Overall, this case was a good learning experience & $\begin{array}{l}\text { Hoelscher and } \\
\text { Mortimer (2018) }\end{array}$ \\
\hline Q8 & $\begin{array}{c}\text { I am more comfortable with using Tableau for data } \\
\text { analytics }\end{array}$ & $\begin{array}{l}\text { Hoelscher and } \\
\text { Mortimer (2018) }\end{array}$ \\
\hline Q9 & $\begin{array}{c}\text { I am more comfortable creating data visualizations in } \\
\text { Tableau than in Excel }\end{array}$ & $\begin{array}{l}\text { Hoelscher and } \\
\text { Mortimer (2018) }\end{array}$ \\
\hline Q10 & $\begin{array}{c}\text { I have a better understanding of how data analytics and } \\
\text { data visualizations can help make better business } \\
\text { decisions }\end{array}$ & $\begin{array}{l}\text { Hoelscher and } \\
\text { Mortimer (2018) }\end{array}$ \\
\hline
\end{tabular}

Source: Research data. 
The items were extracted from Hoelscher and Mortimer's (2018) and Igou and Coe's (2016) surveys, comprising a total of ten case-related and Tableaurelated questions (Table 1 ). Students answered these questions based on five categories: totally disagree (TD), somewhat disagree (SD), neutral (N), somewhat agree (SA), and totally agree (TA). After these ten items, a final open-ended question was asked to collect general comments, critiques, compliments, and other students' considerations about the case and Tableau. This last question did not require a mandatory answer.

In the beginning of the study, all participants signed the consent form, which included information about the research's objective, method, confidentiality aspects, participants' risks and benefits, and other issues. In the end of the consent form, the authors also provided their contact information for eventual questions that participants could have on the research.

\section{RESULTS}

Table 2 shows the results concerning students' self-reported proficiency levels in Excel, Tableau, and statistical software packages before (Panel A) and after (Panel B) the use of the Ivana's ice cream case. In Panel A, most of the students reported having an intermediate knowledge in Excel (EXC-B; 75.6\%). Individuals' first contact with Excel may occur even before they enter the higher education and it is a well-known tool to make calculations and organize personal finance, for example. Due to this, students reported higher proficiency levels in Excel than in other types of software. In Panel B, students' perception regarding their proficiency level in Excel (EXC-A) lowered a little bit. Five (12.2\%) students considered their proficiency level in Excel to be Basic after the case, instead of four students $(9.8 \%)$ before the case. It may be due to some adjustments in students' perceptions when answering the proficiency level questions before and after the case. Despite that, it is not a significant change in the results for Excel.

In Panel A, students declared that they are not familiar with Tableau (TABB) or statistical packages (STA-B), as 28 (68.3\%) students reported an inexistent proficiency level in these types of software. This result is in line with Hoelscher and Mortimer's (2018) and it suggests that accountants have little knowledge about how to convert big data into relevant information (Coyne et al., 2018). Indeed, 
students have less contact with these types of software packages even after entering the job market. However, the business profession, and particularly the accounting one, is demanding more skilled professionals in data analytics that are able to run algorithms for financial analysis purposes, especially decision three, regression, and cluster analyses (Kokina, Pachamanova, \& Corbett, 2017). Thus, in the near future, these numbers are expected to be considerably higher. In Panel $B$, it is possible to observe a relevant change in students' perception with respect to their proficiency level in Tableau (TAB-A). After the case, 35 (85.4\%) students reported a Basic level in Tableau, while it was only $19.5 \%$ of the students before the case. This is a preliminary evidence that supports the effectiveness of the Ivana's ice cream case in developing students' skills. Notably, students have gained a basic notion on how to manage Tableau and, therefore, their perception changed from None to Basic after the case.

In regard to proficiency level in statistical packages, there was a little change in students' perception. When comparing STA-B and STA-A, there is a little increase in students' self-reported proficiency level. The main change is in the Basic level (from $24.4 \%$ to $29.3 \%$ ). This result is expected because the case only demanded the use of Tableau. However, even using only this data visualization software, some students thought it helped to gain knowledge in statistical packages as well, especially because statistical software packages generate graphs and other visual analyses that may be similar to those generated by the Tableau.

Table 2: Student proficiency level

\begin{tabular}{|c|c|c|c|c|c|c|c|c|c|c|}
\hline \multicolumn{11}{|c|}{ Panel A: Before Case } \\
\hline \multirow{2}{*}{ Question } & \multicolumn{2}{|c|}{ None } & \multicolumn{2}{|c|}{ Basic } & \multicolumn{2}{|c|}{ Intermediate } & \multicolumn{2}{|c|}{ Advanced } & \multicolumn{2}{|c|}{ Total } \\
\hline & Freq. & $\%$ & Freq. & $\%$ & Freq. & $\%$ & Freq. & $\%$ & Freq. & $\%$ \\
\hline $\begin{array}{c}\text { Excel } \\
\text { (EXC-B) }\end{array}$ & 0 & 0.0 & 4 & 9.8 & 31 & 75.6 & 6 & 14.6 & 41 & 100.0 \\
\hline $\begin{array}{l}\text { Tableau } \\
\text { (TAB-B) }\end{array}$ & 28 & 68.3 & 8 & 19.5 & 4 & 9.8 & 1 & 2.4 & 41 & 100.0 \\
\hline $\begin{array}{l}\text { Statistics } \\
\text { (STA-B) }\end{array}$ & 28 & 68.3 & 10 & 24.4 & 2 & 4.9 & 1 & 2.4 & 41 & 100.0 \\
\hline \multicolumn{11}{|c|}{ Panel B: After Case } \\
\hline \multirow{2}{*}{ Question } & \multicolumn{2}{|c|}{ None } & \multicolumn{2}{|c|}{ Basic } & \multicolumn{2}{|c|}{ Intermediate } & \multicolumn{2}{|c|}{ Advanced } & \multicolumn{2}{|c|}{ Total } \\
\hline & Freq. & $\%$ & Freq. & $\%$ & Freq. & $\%$ & Freq. & $\%$ & Freq. & $\%$ \\
\hline $\begin{array}{c}\text { Excel } \\
(\text { EXC-A) }\end{array}$ & 0 & 0.0 & 5 & 12.2 & 30 & 73.2 & 6 & 14.6 & 41 & 100.0 \\
\hline $\begin{array}{l}\text { Tableau } \\
(\text { TAB-A) }\end{array}$ & 0 & 0.0 & 35 & 85.4 & 5 & 12.2 & 1 & 2.4 & 41 & 100.0 \\
\hline $\begin{array}{l}\text { Statistics } \\
(\text { STA-A) }\end{array}$ & 25 & 61.0 & 12 & 29.3 & 3 & 7.3 & 1 & 2.4 & 41 & 100.0 \\
\hline
\end{tabular}


Note. EXC-B, TAB-B, and STA-B are, respectively, the names of the variables for proficiency level in Excel, Tableau, and Statistical software packages before the case and EXC-A, TAB-A, and STA-A are the names of the variables after the case.

Source: Research data.

Table 3 shows the response frequencies of the ten case-related and Tableau-related questions. In general, it is observable that the students either somewhat agreed or totally agreed with the items. For Q1, 51.2\% somewhat agreed and $48.8 \%$ totally agreed with the statement that the case was engaging and interesting. This evidence suggests that the case itself presented some features that made students like it. This finding is congruent with prior studies (Hoelscher \& Mortimer, 2018; Igou \& Coe, 2016). Similarly, students also reported to agree with Q2. It indicates that the case was efficient to show how data analysis can be used to answer key issues of businesses. Igou and Coe (2016) obtained a similar result.

Students generally agreed that the use of Ivana's ice cream case had efficacy to understand the Tableau software and to develop skills and knowledge related to data analysis (items Q3 and Q4). In item Q3, 97.5\% of the students declared to somewhat agree or totally agree, while in item Q4 all students reported to somewhat agree or totally agree with it. These results suggest that not only the case itself has efficacy to help students obtain data analysis skills, but also that the professor utilized it adequately. The low level of proficiency previously reported by the students may have played a role in students' responses as well. Because students did not know how to use these software packages efficiently prior to the application of the case (STA-B, see Table 2), they were more likely to be benefited from such activity, which in turn it could explain why students were also more prone to recommend its usage for future classes (item Q5).

Item Q6 stated that "I used a variety of skills to solve this case." Except for one student $(2.4 \%)$ who responded neutrally, all of them reported to partially or fully agree with it. This evidence is congruent with Hoelscher and Mortimer's (2018). Indeed, the case demands a set of skills from students to answer its questions. At first, it can represent a significant challenge from them. But as they practice how to use the software, data visualization and interpretation becomes more natural. And here is an essential point that accounting educators must explore. Using multiple and different cases can encourage the development of students' skills and knowledge about data analytic tools. 
Results from Q7 supported that the students considered the case as a positive learning experience. Seventeen (41.5\%) students somewhat agreed and twenty-three fully agreed with it. Likewise, Hoelscher and Mortimer (2018) found an average of 6.50 points (out of 7.00 ) for this item, with a standard deviation of 0.64 points. This result may be related to $\mathrm{Q} 1$, for which it was found that the case was engaging and interesting.

With only four (9.8\%) students responding in a neutral way, Q8 obtained a high level of students' agreement. Sixteen (39.0\%) students totally agreed and twenty-one partially agreed with the following statement: "I am more comfortable with using Tableau for data analytics." Despite the neutral answers, most of the students declared to be more comfortable using Tableau. And, perhaps because of this, students generally agreed with Q9, which stated that they were more comfortable creating data visualizations in Tableau than in Excel. Whilst one $(2.4 \%)$ student answered totally disagree, another one (2.4\%) somewhat disagree, and other eight (19.5\%) responded neutrally, the answers concentrated on "somewhat agree" (43.9\%) and "totally agree" (31.7\%) categories. Similar response pattern was obtained by Hoelscher and Mortimer (2018) regarding Q8 and Q9.

These results suggest that students got more familiar with Tableau. However, findings for Q9 deserve attention in their interpretation because one could find hard to believe that after only one three-hour session students would be more skilled in using Tableau than in Excel to visualize data. In this regard, once students get the data imported by Tableau, it automatically generates graphics and other types of visual analysis. On the other hand, Excel demands students to select the data in the cells before developing graphics. Editing them in Excel may also be confusing. Thus, students' perceptions might have been more sensitive to these aspects when responding to item Q9. A critical perspective on this point is understandable, though.

Finally, $97.6 \%$ of the students partially or fully agreed with Q10. This finding supports that the Ivana's ice cream case assisted students to better understand how data analysis and visualization using Tableau can improve business decisions. This result is aligned with Hoelscher and Mortimer's (2018). 
Table 3: Response frequency

\begin{tabular}{|c|c|c|c|c|c|c|c|c|c|c|c|c|}
\hline \multirow{2}{*}{ Item } & \multicolumn{2}{|c|}{ TD } & \multicolumn{2}{|c|}{ SD } & \multicolumn{2}{|c|}{$\mathbf{N}$} & \multicolumn{2}{|c|}{ SA } & \multicolumn{2}{|c|}{ TA } & \multicolumn{2}{|c|}{ Total } \\
\hline & Freq. & $\%$ & Freq. & $\%$ & Freq. & $\%$ & Freq. & $\%$ & Freq. & $\%$ & Freq. & $\%$ \\
\hline Q1 & 0 & 0.0 & 0 & 0.0 & 0 & 0.0 & 21 & 51.2 & 20 & 48.8 & 41 & 100.0 \\
\hline Q2 & 0 & 0.0 & 0 & 0.0 & 0 & 0.0 & 20 & 48.8 & 21 & 51.2 & 41 & 100.0 \\
\hline Q3 & 0 & 0.0 & 0 & 0.0 & 1 & 2.4 & 19 & 46.3 & 21 & 51.2 & 41 & 100.0 \\
\hline Q4 & 0 & 0.0 & 0 & 0.0 & 0 & 0.0 & 20 & 48.8 & 21 & 51.2 & 41 & 100.0 \\
\hline Q5 & 0 & 0.0 & 0 & 0.0 & 1 & 2.4 & 17 & 41.5 & 23 & 56.1 & 41 & 100.0 \\
\hline Q6 & 0 & 0.0 & 0 & 0.0 & 4 & 9.8 & 23 & 56.1 & 14 & 34.1 & 41 & 100.0 \\
\hline Q7 & 0 & 0.0 & 0 & 0.0 & 0 & 0.0 & 17 & 41.5 & 24 & 58.5 & 41 & 100.0 \\
\hline Q8 & 0 & 0.0 & 0 & 0.0 & 4 & 9.8 & 21 & 51.2 & 16 & 39.0 & 41 & 100.0 \\
\hline Q9 & 1 & 2.4 & 1 & 2.4 & 8 & 19.5 & 18 & 43.9 & 13 & 31.7 & 41 & 100.0 \\
\hline Q10 & 0 & 0.0 & 0 & 0.0 & 1 & 2.4 & 25 & 61.0 & 15 & 36.6 & 41 & 100.0 \\
\hline
\end{tabular}

Note. TD = Totally disagree; SD = Somewhat disagree; $\mathrm{N}=$ Neutral; SA = Somewhat agree; TA = Totally agree.

Source: Research data.

To further explore students' perceptions, chi2 tests were performed to analyze the association between students' demographic information, their proficiency levels, and the responses of the case-related and Tableau-related questions (Q1 through Q10). Results were analyzed considering a significance level of .05 . Table 4 reports the results.

Table 4: Association tests among demographic, proficiency level, case-related, and Tableau-related questions

\begin{tabular}{cccccccccc}
\hline $\begin{array}{c}\text { Chi2 } \\
\text { tests }\end{array}$ & SEX $^{(\mathrm{A})}$ & AGE2(B) & MAJ(C) & EXC-B & TAB-B & STA-B & EXC-A & TAB-A & STA-A \\
\hline AGE2(B) & 1.20 & & & & & & & & \\
MAJ(C) $^{(\mathrm{C})}$ & 5.02 & 4.14 & & & & & & & \\
EXC-B & 3.45 & 1.68 & 0.60 & & & & & & \\
TAB-B & 3.76 & 1.12 & 2.98 & $12.64 *$ & & & & & \\
STA-B & 6.87 & 1.95 & 2.12 & 10.80 & $50.43^{* *}$ & & & & \\
EXC-A & 4.05 & 4.05 & 0.28 & $42.33^{* *}$ & $11.35^{*}$ & $11.24 *$ & & & \\
TAB-A & 3.50 & 1.43 & 1.76 & $9.75^{*}$ & $49.54^{* *}$ & $44.92^{* *}$ & $16.48 * *$ & & \\
STA-A & 4.61 & 1.68 & 6.45 & 7.88 & $47.48^{* *}$ & $55.57 * *$ & 10.42 & $64.41 * *$ & \\
Q1 & 0.61 & 1.97 & 0.91 & 0.01 & 6.05 & 3.52 & 0.18 & 1.21 & 2.64 \\
Q2 & 0.22 & 1.21 & 0.91 & 0.01 & $9.27 *$ & 0.98 & 0.31 & 3.04 & 3.00 \\
Q3 & 1.08 & 2.72 & 0.64 & 1.80 & $12.73^{*}$ & 4.21 & 2.99 & 3.43 & 4.58 \\
Q4 & 0.22 & 1.21 & 0.09 & 1.27 & $9.27 *$ & 0.98 & 2.31 & 3.04 & 3.00 \\
Q5 & 1.55 & 1.55 & 1.51 & 0.64 & 12.34 & 6.03 & 1.41 & 1.60 & 5.27 \\
Q6 & 2.21 & 2.16 & 0.48 & 2.09 & 4.87 & 9.00 & 5.30 & 2.97 & $14.72 *$ \\
Q7 & 0.04 & $4.36 *$ & 0.64 & 0.40 & $9.73^{*}$ & 0.80 & 1.17 & 4.03 & 3.27 \\
Q8 & 1.41 & 4.42 & 3.61 & 4.79 & 11.93 & 3.33 & 0.93 & 2.70 & 2.26 \\
Q9 & 2.94 & 4.67 & 3.08 & 12.02 & 10.30 & $23.27 *$ & 8.78 & 2.97 & 8.10 \\
Q10 & 1.40 & 1.94 & 5.04 & 0.72 & 5.74 & 2.57 & 1.28 & 2.56 & 3.91 \\
\hline
\end{tabular}

Note. (A) SEX = student's sex. ${ }^{(B)}$ AGE2 $=$ students' age was divided into two groups from the median: (i) up to 26 years; and (ii) above 26 years (the authors named this dichotomous variable AGE2). (C) MAJ = student's major (academic background).

The numbers represent the chi2 values of the association between each pair of variables.

The level of significance is represented by asterisks: $* * p<.01 ; * p<.05$.

Source: Research data. 
The interpretation of the results in Table 4 begins in the leftmost column (SEX) and ends in the rightmost (STA-A) column. The SEX variable is not significantly associated with any other variable $(p>.05)$. It means that none of the student sex categories are more (less) associated with a certain proficiency level, case-related, or Tableau-related question category.

The AGE2 variable is only relevantly associated with Q7 (chi2 $=4.36$; $\mathrm{p}<$ .05). The cross-tabulation between AGE2 and Q7 (not reported) indicated that older students (above 26 years) were more prone to totally agree with Q7, while younger students (up to 26 years) were more prone to partially agree with it. It suggests that older students agreed more intensely that the case was a positive learning experience than younger students. It may be due to the lack of opportunity, by older students, to learn from educational cases. Thus, they rated Q7 more intensely. Another potential explanation is that older students have more professional experience than younger ones, making them the ones who would presumably know how to make the most of the case.

The MAJ variable is not associated with any other variable at the 0.05 level. This is an interesting finding because one could anticipate that accounting majors (63.41\% of the students, see 3.1 subsection) would find the case more engaging and productive. However, this evidence supports that the responses to the caserelated and Tableau-related questions were provided independently from the MAJ categories (accounting, management, and other) since no significant association was identified. Then, this evidence suggests that the case was perceived similarly by students with distinct academic backgrounds.

EXC-B is significantly associated with EXC-A. The relationship between EXC-B and EXC-A was expected since they both represent the students' perception on the proficiency level in Excel before and after the case. As shown in Table 2, EXC-B and EXC-A obtained a similar distribution of the responses. EXC-B also presented a material association with TAB-B and TAB-A. It suggests that students' responses were not provided randomly. Through their cross-tabulation tables (not reported), it was identified that, while students reported low ("none" or "basic") proficiency levels in Tableau, these same students were more inclined to report an intermediate level in Excel.

TAB-B was found to be significantly associated with STA-B, EXC-A, TAB-A, STA-A, Q2, Q3, Q4, and Q7. These results were expected once Tableau software Future Studies Research Journal ISSN 2175-5825 SÃo Paulo, v.11, N.3, P. 305 - 329, Sep. / Dec. 2019 
was used to solve the case's exercises and, therefore, students' initial proficiency level in Tableau would be related to the case-related questions (i.e., Q2, Q3, Q4, and Q7). Tableau runs visual analysis that are similar to other types of analyses performed by other statistical packages. It can explain why students' initial proficiency level in Tableau is related to the proficiency levels in statistical packages and Excel. Finally, TAB-B and TAB-A were also expected to be related once they both represent the students' proficiency level in Tableau before and after the case.

The STA-B variable has found to be significantly associated with EXC-A, TAB-A, STA-A, and Q9. The main result from the cross-tabulation between STA-B and EXC-A (not reported) indicated that students' low ("none" or "basic") proficiency levels in statistical packages before the case was associated with their intermediate proficiency level in Excel after the case. Students' initial knowledge of statistical packages in general may have an influence on how students perceive how proficient they are in Excel, even after completing an activity that involves other statistical software packages (i.e., Tableau). The cross-tabulation between STA-B and TAB-A (not reported) suggested that the category "none" of STA-B is more associated with the category "basic" of TAB-A. This result supports that students' initial proficiency level in statistical packages may have an influence on their perceptions regarding their skills towards Tableau. Prior knowledge about statistical packages in general may help students to use and develop skills to manage Tableau. The association between STA-B and STA-A is expected because both variables represent the students' proficiency level in statistical software packages before and after the case. Interestingly, STA-B and Q9 were relevantly associated as well. The main result from the cross-tabulation of these variables (not reported) suggested that the category "none" of STA-B are more associated with the categories "somewhat agree (SA)" and "totally agree (TA)" of Q9. Although students may not be initially proficient in statistical packages, they thought they are more comfortable generating visual analysis in Tableau rather than in Excel. This evidence indicates that the Ivana's ice cream case helped students to acquire some skills to manage Tableau to the point that they found easier to visualize data when using it. Despite that, Q9 specifically asked about data visual analysis. Students may still prefer Excel to make other types of operations. 
EXC-A is significantly associated with EXC-B, TAB-B, and STA-B, which were interpreted previously. Moreover, EXC-A is also associated with TAB-A. The cross-tabulation between these two variables (not reported) showed that the category "intermediate" of EXC-A is more associated with the category "basic" of TAB-A. Students who have answered intermediate for the Excel question also have answered basic for TAB-A one.

TAB-A is significantly associated with EXC-B, TAB-B, STA-B, and EXC-A, which were interpreted previously. Besides that, TAB-A is also strongly associated with STA-A. The cross-tabulation between these two variables (not reported) indicated that the students' low (basic) proficiency level in Tableau after the case is more associated with low proficiency levels ("none" and "basic") in statistical packages after the case as well. Even though the students' proficiency level in Tableau has increased after the case, it still needs improvement, as well as their proficiency level in statistical packages.

Finally, the STA-A variable is significantly associated with TAB-B, STA-B, and TAB-A, which were interpreted previously. In addition, STA-A is also associated with Q6. When analyzing the cross-tabulation (not reported), it is notable that the category "none" of TAB-A is more associated with the category "somewhat agree (SA)" of Q6 and the category "basic" of TAB-A is more associated with the category "totally agree (TA)" of Q6. Despite the low proficiency level in statistical packages, students agreed that they used a variety of skills to solve the Ivana's ice cream case. In Table 2, results showed that students possessed low proficiency levels in Tableau and statistical packages. However, after the case, students challenged their lack of proficiency level in these tools to solve the case, making them to use a variety of skills.

After performing the chi2 tests, a Spearman's correlation analysis was carried out, focusing only on the case-related and Tableau-related questions (Q1 through Q10). Table 6 shows the results.

Table 6: Spearman's correlation matrix between case-related and Tableau-related questions

\begin{tabular}{|c|c|c|c|c|c|c|c|c|c|c|}
\hline & Q1 & Q2 & Q3 & $\mathrm{Q} 4$ & Q5 & Q6 & Q7 & Q8 & Q9 & Q10 \\
\hline Q1 & 1.00 & & & & & & & & & \\
\hline Q2 & $0.86 * *$ & 1.00 & & & & & & & & \\
\hline Q3 & $0.66 * *$ & $0.80 * *$ & 1.00 & & & & & & & \\
\hline Q4 & $0.76^{* *}$ & $0.90 * *$ & $0.90 * *$ & 1.00 & & & & & & \\
\hline Q5 & $0.76^{* *}$ & $0.80 * *$ & $0.73 * *$ & $0.80 * *$ & 1.00 & & & & & \\
\hline
\end{tabular}




\begin{tabular}{ccccccccccc} 
Q6 & $0.44^{* *}$ & $0.51^{* *}$ & $0.45^{* *}$ & $0.51^{* *}$ & $0.63^{* *}$ & 1.00 & & & & \\
Q7 & $0.72 * *$ & $0.86^{* *}$ & $0.72 * *$ & $0.86^{* *}$ & $0.71^{* *}$ & $0.38^{*}$ & 1.00 & & & \\
Q8 & $0.72 * *$ & $0.70^{* *}$ & $0.63^{* *}$ & $0.70^{* *}$ & $0.66^{* *}$ & $0.37^{*}$ & $0.65^{* *}$ & 1.00 & & \\
Q9 & $0.56 * *$ & $0.50^{* *}$ & $0.35^{*}$ & $0.43^{* *}$ & $0.35^{*}$ & 0.27 & $0.48^{* *}$ & $0.68^{* *}$ & 1.00 & \\
Q10 & $0.68^{* *}$ & $0.58^{* *}$ & $0.58^{* *}$ & $0.68^{* *}$ & $0.52^{* *}$ & $0.41^{* *}$ & $0.59^{* *}$ & $0.79 * *$ & $0.68 * *$ & 1.00 \\
\hline
\end{tabular}

The level of significance is represented by asterisks: $* * p<.01 ; * p<.05$.

Source: Research data.

According to the results in Table 6, all correlations are significant at the .05 level but one. These results were expected because the questions asked about the Ivana's ice cream case and the Tableau software. The combination of these two pedagogic resources formed the activity. Therefore, one could anticipate that the results for these questions would be correlated. For example, Q2 and Q4 are strongly correlated (coef. $=.90 ; \mathrm{p}<.01$ ). It means, from students' perspective, that the case is an effective way to gain an understanding of how data analytics can be used to answer important business questions (Q2) and at the same time is an effective way to develop skills and knowledge related to data analytics (Q4). If one develops his/her skills and knowledge on data analytics, he/she is more prone to use it to answer key business questions.

The only correlation that is not significant is between Q6 and Q9 ( $p>.05)$. A potential explanation is that Q6 asks about the skills to solve the case, while Q9 asks about Tableau in comparison with Excel (see Table 1 for questions' description). Despite this lack of significance, the overall results are congruent with the authors' expectations.

Ultimately, some students responded the open-ended question. Because it was not mandatory, not all students answered it. However, those who did, they provided us valuable feedback that is shown in Table 6.

Table 6: Students' comments on the case and Tableau software

\section{Students' additional comments}

One more tool (Tableau) that I learned, the system is very useful (student 2).

Very easy to understand the system (Tableau). Even in a practical and rapid way, I learned the basics already (student 4 ).

This tool (Tableau) is highly valuable for learning. I recommend its usage for the next classes of students (student 5).

I found it great, I am very curious and certainly will explore to know more about Tableau...; As a suggestion, I think it had to be free for all to have access to this excellent tool of assessment and planning for companies (student 9).

It was a great experience; I would like more time to practice it (Tableau) (student 18). Simple layout, very well thought (student 19).

To have a class with more time to use the software to learn more of its resources, if possible (student 21).

I found the tool (Tableau) very interesting to run analyses of a certain company; A rapid and easy way to run data analysis (student 32 ). 
It is a very practical activity, transmitting both theoretical accounting concepts and software usage concepts. The activity was something very interesting that involved the student. For a Saturday class, it is totally suitable (student 33).

The suggestion is to use this type of class/case with all accounting students at the university since the experience brings new perceptions on technology usage to the student that are needed in a daily professional life (student 41 ).

Source: Research data.

The students' comments were more concentrated on Tableau. Even using it for the first time, some of them thought it was easy to use (students 4 and 32). While students 18 and 21 asked for more time to practice it, others highlighted its usefulness (students 2, 5, 33, 41). Student 9 also observed that Tableau is not free. It may be a potential difficulty for educational institutions to embrace it. However, there is the trial version and a free license for using Tableau for educational purposes that can help in this sense.

\section{CONCLUDING REMARKS}

The study's objective was to analyze lato sensu business students' perceptions on an accounting big data case. The Ivana's ice cream case developed by Hoelscher and Mortimer (2018) was chosen and implemented in two lato sensu graduate programs in Brazil, involving a total of 41 participants. After the case's application, surveys were administered to collect data.

Results showed that the students reported having a low initial proficiency level in using Tableau and statistical software packages before the case, even though most of them declared an intermediate proficiency level in Excel. This evidence may have made the case more crucial for them since they had to run analyses using a software package that they were not familiar with and, therefore, adding more value in terms of skill development. After the case, students' perceptions changed from "none" to "basic" in terms of proficiency level in Tableau, which indicates that the case helped them to increase their skill to use Tableau.

Also, students perceived the case's application positively. Survey's items indicated that the case was engaging and interesting, providing a good learning experience. Most of the association tests showed no significance. This evidence supports that the case was perceived similarly by the students, regardless their demographic characteristics. Spearman's correlation matrix also showed consistent results regarding the usefulness of the case and the Tableau software. 
Ultimately, students' comments reinforced the positive learning experience and provided feedback for improving teaching quality.

The findings of this study have important implications for business and accounting education. As one of the first experiences in teaching big data for business - and especially accounting - students in Brazil, the evidence supports that the case was useful for lato sensu students, albeit it is intended to be employed in a basic data visualization course (Hoelscher \& Mortimer, 2018). Second, although it was an accounting case, students with different academic background reported similar perceptions as no significant associations were found between the categories of the demographic variables and the questions. Thus, even for students who majored in non-accounting disciplines, the case was productive. Finally, qualitative data showed how to improve the teaching quality, specifically concerning Tableau's practice time. Even though case was developed in only one class, perhaps other instructors should consider applying the case in more than on meeting.

Some limitations did exist in this study, and the following points should be emphasized: (i) surveys are susceptible to some response bias that the researchers do not always have control, such as halo effect, social desirability response bias, and others. Then, students were asked to provide honest responses, especially because the data would be treated anonymously; (ii) the empirical literature on big data teaching in accounting is still in its early stage, particularly in Brazil. Thus, it limited our results' discussion with prior similar studies; (iii) the sample was relatively small. It is encouraged to apply the case with a higher number of business or accounting professionals and students; and (iv) the entire case was developed over a three-hour class.

There are many possibilities to develop it, as Hoelscher and Mortimer (2018) describe in their study (see implementation guidance and alternative implementation guidance subsections). The authors of this study only scratched the surface of deeper ways to implement the case. Then, the authors encourage professors to apply the case in distinct manners to better understand how to make the most of it.

Finally, besides those already provided, the suggestions for future studies include the replication of accounting big data educational cases in different settings (e.g., executive education, undergraduate courses, stricto sensu courses, and so 
on); the usage of educational theories and taxonomies (e.g., Bloom's) to evaluate students' learning from the cases; and the usage of Lindell's (2018) four types of data analytics to evaluate the set of data analytic skills the cases develop in students.

As the world of technology gets more sophisticated, accounting must follow its trends. Big data has become a topic that is bringing challenges to both business practitioners and educators, but also key opportunities for the professions to evolve. In order to do that, accounting educators must take initiatives toward the updated topics that are emerging and affecting the profession, and big data is certainly a subject that accounting cannot ignore.

\section{REFERENCES}

Alles, M., \& Gray, G. L. (2016). Incorporating big data in audits: Identifying inhibitors and a research agenda to address those inhibitors. International Journal of Accounting Information Systems, 22, 44-59. https://doi.org/10.1016/j.accinf.2016.07.004

Beaver, D., Kumar, S., Li, H. C., Sobel, J., \& Vajgel, P. (2010). Finding a needle in Haystack: Facebook's photo storage. Proceedings of the 9th USENIX Symposium on Operating Systems Design and Implementation (OSDI'10), (October), 1-8. Retrieved from http://www.usenix.org/events/osdi/tech/full_papers/Beaver.pdf

Bello-Orgaz, G., Jung, J. J., \& Camacho, D. (2016). Social big data: Recent achievements and new challenges. Information Fusion, 28, 45-59. https://doi.org/10.1016/j.inffus.2015.08.005

Blazquez, D., \& Domenech, J. (2018). Big Data sources and methods for social and economic analyses. Technological Forecasting and Social Change, 130(September 2017), 99-113. https://doi.org/10.1016/j.techfore.2017.07.027

Brown-Liburd, H., \& Vasarhelyi, M. A. (2015). Big Data and Audit Evidence. Journal of Emerging Technologies in Accounting, 12(1), 1-16. https://doi.org/10.2308/jeta10468

Cao, M., Chychyla, R., \& Stewart, T. (2015). Big Data Analytics in Financial Statement Audits. Accounting Horizons, 29(2), 423-429. https://doi.org/10.2308/acch-51068

Coyne, E. M., Coyne, J. G., \& Walker, K. B. (2018). Big Data information governance by accountants. International Journal of Accounting \& Information Management, 26(1), 153-170. https://doi.org/10.1108/IJAIM-01-2017-0006

Earley, C. E. (2015). Data analytics in auditing: Opportunities and challenges. Business Horizons, 58(5), 493-500. https://doi.org/10.1016/j.bushor.2015.05.002

Gandomi, A., \& Haider, M. (2015). Beyond the hype: Big data concepts, methods, and analytics. International Journal of Information Management, 35(2), 137-144. 
https://doi.org/10.1016/j.ijinfomgt.2014.10.007

Günther, W. A., Rezazade Mehrizi, M. H., Huysman, M., \& Feldberg, F. (2017). Debating big data: A literature review on realizing value from big data. The Journal of Strategic Information Systems, 26(3), 191-209. https://doi.org/10.1016/j.jsis.2017.07.003

Hoelscher, J., \& Mortimer, A. (2018). Using Tableau to visualize data and drive decisionmaking. Journal of Accounting Education, 44(October 2017), 49-59. https://doi.org/10.1016/j.jaccedu.2018.05.002

Igou, A., \& Coe, M. (2016). Vistabeans coffee shop data analytics teaching case. Journal of Accounting Education, 36, 75-86. https://doi.org/10.1016/j.jaccedu.2016.05.004

Janvrin, D. J., Raschke, R. L., \& Dilla, W. N. (2014). Making sense of complex data using interactive data visualization. Journal of Accounting Education, 32(4), 31-48. https://doi.org/10.1016/j.jaccedu.2014.09.003

Janvrin, D. J., \& Watson, M. W. (2017). "Big Data": A new twist to accounting. Journal of Accounting Education, 38, 3-8. https://doi.org/10.1016/j.jaccedu.2016.12.009

Kokina, J., Pachamanova, D., \& Corbett, A. (2017). The role of data visualization and analytics in performance management: Guiding entrepreneurial growth decisions. Journal of Accounting Education, 38, 50-62. https://doi.org/10.1016/j.jaccedu.2016.12.005

Krahel, J. P., \& Titera, W. R. (2015). Consequences of Big Data and Formalization on Accounting and Auditing Standards. Accounting Horizons, 29(2), 409-422. https://doi.org/10.2308/acch-51065

Laney, D. (2001). 3D data management: Controlling data volume, velocity and variety. META Group Research Note, 6(70), 1. Retrieved from https://www.bibsonomy.org/bibtex/742811cb00b303261f79a98e9b80bf49

Lindell, J. (2018). Analytics and Big Data for Accountants. New York, NY: American Institute of Certified Public Accountants, https://doi.org/10.1002/9781119512356

Pathways Commission. (2012). The Pathways Commission: Charting a national strategy for the next generation of accountants. Retrieved from http://commons.aaahq.org/posts/a3470e7ffa

Pincus, K. V., Stout, D. E., Sorensen, J. E., Stocks, K. D., \& Lawson, R. A. (2017). Forces for change in higher education and implications for the accounting academy. Journal of Accounting Education, 40, 1-18. https://doi.org/10.1016/j.jaccedu.2017.06.001

Richins, G., Stapleton, A., Stratopoulos, T. C., \& Wong, C. (2017). Big Data Analytics: Opportunity or Threat for the Accounting Profession? Journal of Information Systems, 31(3), 63-79. https://doi.org/10.2308/isys-51805

Vasarhelyi, M. A., Kogan, A., \& Tuttle, B. M. (2015). Big Data in Accounting: An Overview. Accounting Horizons, 29(2), 381-396. https://doi.org/10.2308/acch-51071

Wamba, S. F., Gunasekaran, A., Akter, S., Ren, S. J., Dubey, R., \& Childe, S. J. (2017). Big data analytics and firm performance: Effects of dynamic capabilities. Journal of Business Research, 70, 356-365. https://doi.org/10.1016/j.jbusres.2016.08.009

Warren, J. D., Moffitt, K. C., \& Byrnes, P. (2015). How Big Data Will Change Accounting. 
Accounting Horizons, 29(2), 397-407. https://doi.org/10.2308/acch-51069

Yoon, K., Hoogduin, L., \& Zhang, L. (2015). Big Data as Complementary Audit Evidence. Accounting Horizons, 29(2), 431-438. https://doi.org/10.2308/acch-51076

Zhang, J., Yang, X., \& Appelbaum, D. (2015). Toward Effective Big Data Analysis in Continuous Auditing. Accounting Horizons, 29(2), 469-476. https://doi.org/10.2308/acch-51070 